\title{
Low molecular weight heparin versus other anti-thrombotic agents for prevention of venous thromboembolic events after total hip or total knee replacement surgery: a systematic review and meta-analysis
}

\author{
Xin Lu and Jin Lin ${ }^{*}(D)$
}

\begin{abstract}
Background: Venous thromboembolism (VTE) is an important complication following total hip replacement (THR) and total knee replacement (TKR) surgeries. Aim of this study was to comprehensively compare the clinical outcomes of low-molecular-weight heparin $(L M W H)$ with other anticoagulants in patients who underwent TKR or THR surgery.

Methods: Medline, Cochrane, EMBASE, and Google Scholar databases were searched for eligible randomized controlled studies (RCTs) published before June 30, 2017. Meta-analyses of odds ratios were performed along with subgroup and sensitivity analyses.

Results: Twenty-one RCTs were included. In comparison with placebo, LMWH treatment was associated with a lower risk of VTE and deep vein thrombosis (DVT) ( $P$ values $<0.001)$ but similar risk of pulmonary embolism $(P E)(P=0.227)$ in THR subjects. Compared to factor Xa inhibitors, LMWH treatment was associated with higher risk of VTE in TKR subjects $(P<0.001)$, and higher DVT risk $(P<0.001)$ but similar risk of PE and major bleeding in both THR and TKR. The risk of either VTE, DVT, PE, or major bleeding was similar between LMWH and direct thrombin inhibitors in both THR and TKR, but major bleeding was lower with LMWH in patients who underwent THR $(P=0.048)$.
\end{abstract}

Conclusion: In comparison with factor Xa inhibitors, LMWH may have higher risk of VTE and DVT, whereas compared to direct thrombin inhibitors, LMWH may have lower risk of major bleeding after THR or TKR.

Keywords: Low molecular weight heparin, Total knee replacement, Total hip replacement, Bleeding, Thrombosis

\section{Background}

Venous thromboembolism (VTE) is an important complication following total hip replacement (THR) and total knee replacement (TKR) surgeries. The risk of postoperative thromboembolic events was estimated to be approximately $50 \%$ for an asymptomatic event and $15 \%$ to $30 \%$ for a symptomatic event in the absence of prophylactic treatment $[1,2]$. These procedures can also result in deep venous thrombosis (DVT), pulmonary embolism (PE), infection, and death [3]. Asian patients

\footnotetext{
* Correspondence: captainlx@163.com

Department of Orthopaedics, Peking Union Medical College Hospital, Chinese Academy of Medical Sciences and Peking Union Medical College, Beijing, China
}

aged $\geq 40$ years had a significantly higher relative risk of developing DVT, proximal DVT and PE [4].

Anticoagulants are routinely used and recommended after major orthopedic surgery to prevent VTE Anticoagulants has been found to reduce the risk of thromboembolic events by approximately $50 \%$ to $80 \%$ when prescribed prophylactically [1]. Both the American College of Chest Physicians (ACCP) and American Association of Orthopedic Surgeons (AAOS) guidelines for VTE prophylaxis recommend antithrombotic prophylaxis following THR or TKR [2, 4]. However, although pharmacologic thromboprophylaxis in patients with THR or TKR may decrease the incidence of VTE and other thrombus related events, it can cause increased risk of major bleeding [2, 5]. A strong

(c) The Author(s). 2018 Open Access This article is distributed under the terms of the Creative Commons Attribution 4.0 International License (http://creativecommons.org/licenses/by/4.0/), which permits unrestricted use, distribution, and reproduction in any medium, provided you give appropriate credit to the original author(s) and the source, provide a link to the Creative Commons license, and indicate if changes were made. The Creative Commons Public Domain Dedication waiver (http://creativecommons.org/publicdomain/zero/1.0/) applies to the data made available in this article, unless otherwise stated. 
relationship between major bleeding and poor outcome irrespective of the study drug used has been demonstrated [6]. Hence, the trade-offs between fewer symptomatic PE and DVT with thromboprophylaxis versus increased major bleeding should be considered [2, 7].

Current guidelines for thromboprophylaxis recommend the use of vitamin $\mathrm{K}$ antagonists (e.g. warfarin), low-molecular-weight heparins (LMWH), aspirin, or indirect inhibitor of factor Xa [8]. The efficacy and safety of LMWH is well established [5, 9]. It has a long half-life with good bioavailability [9] and is administered once daily subcutaneous dose without laboratory monitoring or dose adjustment. It is safe and effective for extended out-ofhospital prophylaxis after TKR or THR surgery [10]. Disadvantages associated with LMWH include parenteral administration, expense, potential thrombocytopenia, and poor patient adherence $[11,12]$. In a previous meta-analysis, patients who received LMWH (e.g. enoxaparin) prophylaxis had lower incidence of DVT after knee arthroscopic surgery compared to patients who did not receive LMWH prophylaxis [13].

New generation of oral anticoagulants, such as dabigatran etexilate, ximelagatran, rivaroxaban, and apixaban, are now available for prophylaxis against VTE in patients undergoing TKR or THR surgery [14]. Factor Xa inhibitors (i.e., rivaroxaban, darexaban, and apixaban) and direct thrombin inhibitors (i.e., ximelagatran and dabigatran etexilate) have more predictable anticoagulant effects compared to LMWH which also overcome the need to monitor patients receiving short-term thromboprophylaxis [6]. However, disadvantages associated with these drugs include costs and lack of antidotes for timely reversal of bleeding [6].

Currently, there is no comprehensive review to summarize the relative effectiveness of LMWH by comparing it with placebo, factor Xa inhibitors or direct thrombin inhibitors in preventing VTE and incidence of major bleeding when used as thromboprophylaxis agent in TKR or THR surgical interventions. The aim of this meta-analysis was to assess the in-patient clinical outcomes of LMWH compared to factor $\mathrm{Xa}$ inhibitors and direct thrombin inhibitors in TKR or THR surgery subjects.

\section{Methods}

\section{Search strategy}

The study was performed in accordance with the PRISMA guidelines. Following databases were searched for studies published before June 30, 2017: Medline, Cochrane, EMBASE, and Google Scholar. The search term (Hip OR Knee), (replacement OR arthroplasty), (low molecular weight heparin OR enoxaparin), (Venous Thromboembolism OR Pulmonary Embolism OR Vein Thrombosis) AND (inhibitor of factor Xa OR direct thrombin inhibitor) and Randomized controlled trial (RCTs) were used.

\section{Eligibility}

Eligible studies had to have investigated patients undergoing hip or knee arthroplasty or replacement, and to have compared patients receiving LMWH (enoxaparin) with placebo, factor Xa inhibitors or direct thrombin inhibitors. Included studies had to have reported outcomes of interests (given below). Retrospective studies, one arm studies, letters, commentaries, editorials, case reports, proceedings, and personal communications were excluded. Also excluded were studies that evaluated anticoagulants other than direct thrombin and factor Xa inhibitors (e.g. aspirin or warfarin).

\section{Quality assessment}

The quality of the included studies was assessed using Quality in Prognostic Studies (QUIPS), which consists of six domains (study participation, study attrition, prognostic factor measurement, outcome measurement, confounding measurement and account, analysis) $[15,16]$.

\section{Data and statistical analysis}

The following information/data was extracted from studies that met the inclusion criteria: the name of the first author, year of publication, study design, number of participants in each group, participants' age and gender, and major outcomes. The outcomes of interest were the risk or odds of thrombotic events (VTE, DVT, PE, major bleeding). Basic characteristics of the included studies were summarized as mean \pm standard deviations (SD), mean (range: min., max.), or median (min., max.) for age, and $\mathrm{n}(\%)$ for gender and patient number. The outcomes were summarized as $n / N$ (patients with events out of total number of patients) for given intervention as LMWH vs controls (placebo, or factor Xa inhibitor, or a direct thrombin inhibitor). When assessment of an outcome included $\geq 3$ studies, an effect size odd ratio (OR) with corresponding 95\% confidence intervals (95\% CI) was calculated for each individual study and then overall effect size was generated . Meta-analyses was not performed when $\leq 2$ studies reported an outcome of interest. Odds ratios $>1$ implied patients with LMWH treatment had a higher rate of a given outcome than those treated with control; OR $<1$ indicated patients with LMWH treatment had a lower rate of a specific outcome than patients receiving control therapy; $\mathrm{OR}=1$ suggested the rate of an outcome was similar between LMWH and control treatments.

A $\chi^{2}$ test for homogeneity was conducted, and an inconsistency index $\left(\mathrm{I}^{2}\right)$ and $\mathrm{Q}$ statistics were determined [17]. If the $\mathrm{I}^{2}$ statistic was $>50 \%$, a random-effects model (Der Simonian-Laird method) was used [18]. Otherwise, a fixed-effects model (Mantel-Haenszel method) was employed. Combined effects were calculated, and a two-sided $P$ value of $<0.05$ was considered significant. Sensitivity analyses were performed using a leave-one-out 
approach. Publication bias was assessed as guided by the Cochrane Handbook for Systematic and summarized using Review Manager Software (Version 5.3). However, the funnel plot and Egger's test were not performed because the limitation of the study numbers $(\leq 10$ per outcome) [19]. All data were organized in Microsoft Office Excel 2007 spread sheets and all meta-analyses were performed using Comprehensive Meta-Analysis statistical software, version 2.0 (Biostat, Englewood, NJ, USA). Safety analyses were performed with Stata software (version 12, Stata Corporation, Texas, USA).

\section{Results}

\section{Search results}

A total of 184 articles were identified through database searches and nine through corroborative searches (Fig. 1). After removing duplicates and an initial screen of abstracts and titles to remove studies that did not meet the inclusion criteria, 31 studies underwent full text review. Subsequently, 10 articles were excluded due to the ineligible design (retrospective study or commentary) $(n=4)$, being a single-arm study $(n=3)$, and not reporting outcome of interest $(n=3)$. Consequently, 21 studies were included in the systematic review and meta-analysis [10, 20-39].

\section{Characteristics of included studies}

The studies were divided into three subgroups based on the non-LMWH treatment: Group I: LMWH vs. placebo (3 studies); Group II: LMWH vs. direct thrombin inhibitors (8 studies; 4 studies with ximelagatran and 4 with dabigatran etexilate); Group III: LMWH vs. factor Xa inhibitor (10 studies; 6 with studied rivaroxaban, 3 with apixaban, and 1 with darexaban). The study of Kim et al. (2016) had two control groups: rivaroxaban group and placebo group [20]. Therefore, the data from Kim et al. [20] for LMWH vs. placebo were included in meta-analysis of Group I. Group I included 962 participants (708 for LMWH and 254 for placebo), Group II included 18,116 participants (7530 for LMWH and 10,586 for control), and Group III included 26,639 participants (12,713 for LMWH and 13,926 for control). The mean ages for most studies were in general $\geq 60$ years, except for Kim et al. [20]

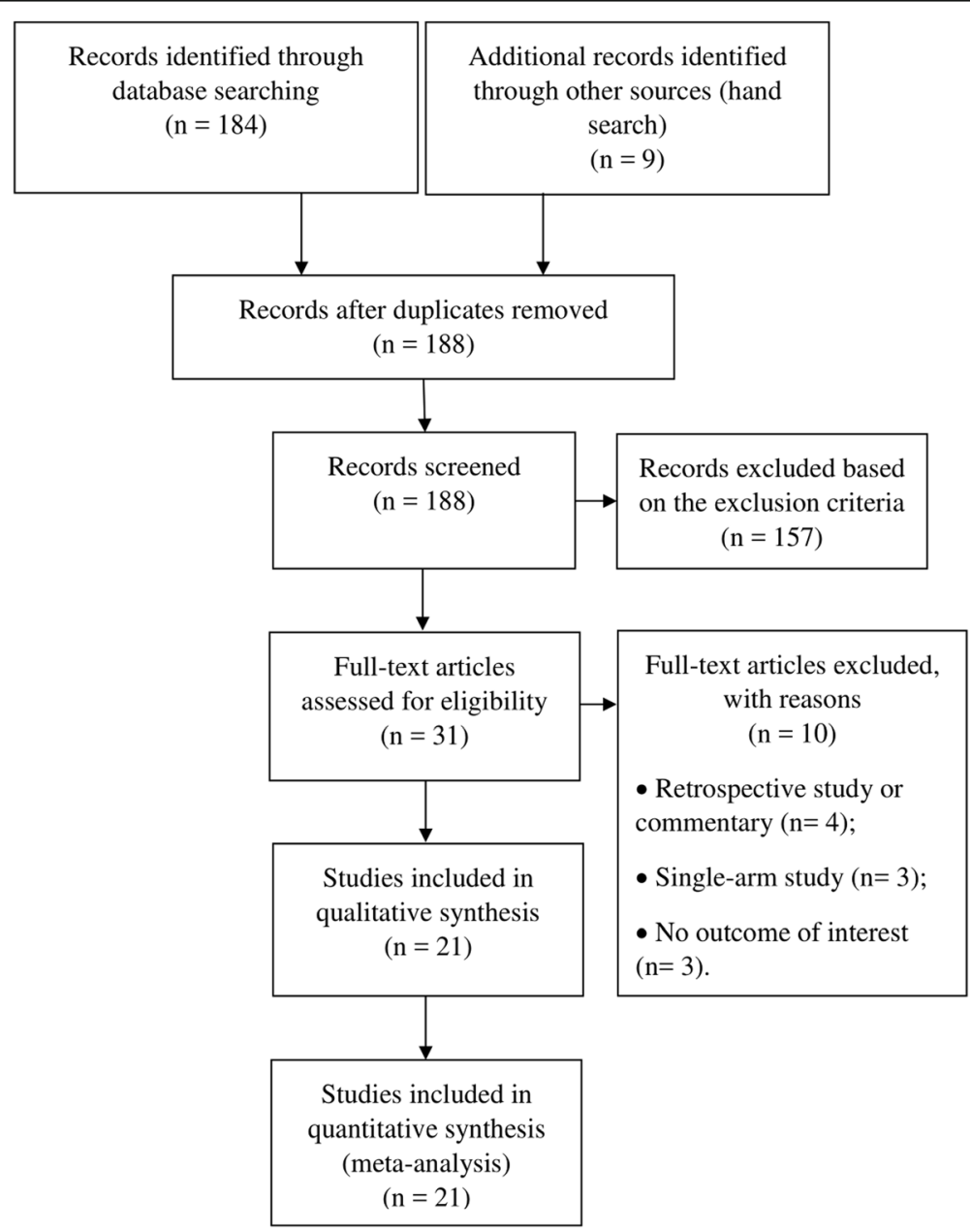

Fig. 1 Flow Diagram for study search 


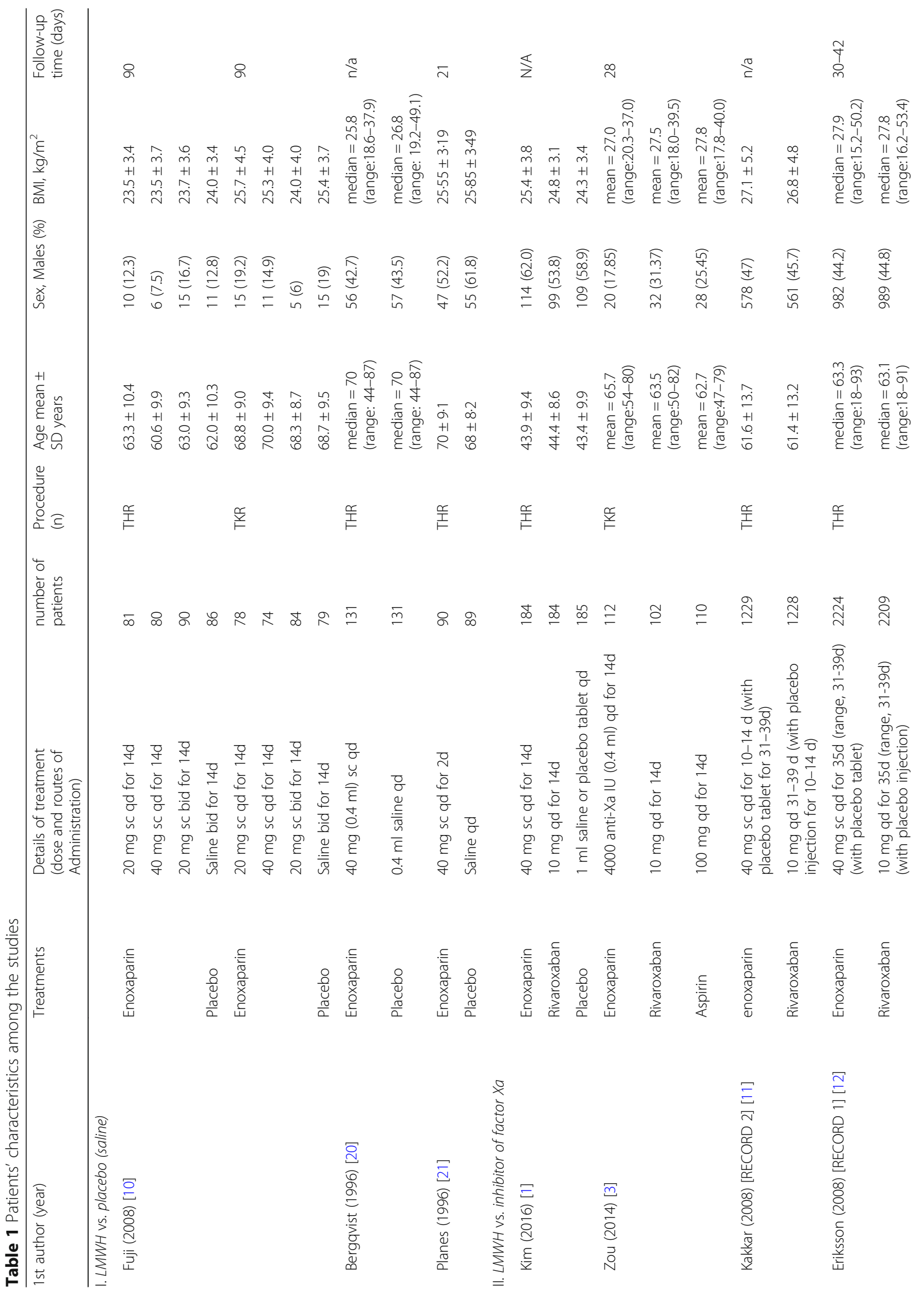


which participants had mean age of about 43 to 44 years. Male patients ranged from 6\% [29] to 62\% [20]. Mean body mass index (BMI) ranged from $23.5 \mathrm{~kg} / \mathrm{m}^{2}$ [29] to $32.6 \mathrm{~kg} / \mathrm{m}^{2}$ [10]. Details are provided in Table 1 .

The drug dose and routes of administration were diverse among the studies. Enoxaparin was the only LMWH used in the included studies at a dose of $40 \mathrm{mg}$ once daily as subcutaneous injection in 15 studies. However, for five studies, the postoperative regimen of $30 \mathrm{mg}$ of enoxaparin administered subcutaneously every $12 \mathrm{~h}$ (30 mg bid) was used as this regimen was approved by the Food and Drug Administration (FDA) [21, 26-28, 36]. Zou et al. [22] used enoxaparin sodium as 4000 anti-Xa activity IU $(0.4 \mathrm{ml})$ once daily dose, and Fuji et al. [29] assessed the effectiveness of three different doses of enoxaparin given subcutaneously; $20 \mathrm{mg}$ qd, $40 \mathrm{mg}$ qd, and $20 \mathrm{mg}$ bid. The length of follow-up period ranged from 12 days (Eriksson et al. [21]) to 90 days (Fuji et al. [29]).

The efficacy and safety outcomes including rate of total VTE, DVT, PE, major bleeding, and clinical relevant non-major bleeding or minor bleeding are summarized in Table 2. In placebo- controlled studies, enoxaparin (LMWH) was associated with lower incidence of major VTE and DVT for both THR and TKR than placebo. In studies in which the effectiveness of enoxaparin was compared with factor Xa inhibitors (i.e., rivaroxaban, apixaban, or darexaban), the incidence of major VTE and DVT in the enoxaparin groups, in general, was lower than in the factor Xa inhibitor groups for both THR and TKR. In studies which compared enoxaparin with direct thrombin inhibitors, enoxaparin appeared to have a higher percentage of patients with major VTE and DVT than ximelagatran but similar or a lower percentage of patients with these events compared with dabigatran etexilate. The percentage of patients with major or minor bleeding for any given treatment appeared to vary across all studies. Results of the meta-analyses are summarized in Additional file 1: Table S1.

\section{Meta-analysis \\ Venous thromboembolism}

In Group I (LMWH vs. placebo), three studies reported complete total VTE data for THR [29, 38, 39]. Fixed effect model was used due to low heterogeneity in the data (THR: $\mathrm{Q}$ value $=2.922, \mathrm{df}=2, P=0.232$, I-squared $=31.56 \%)$. The overall effect size showed that the LMWH treatment had significantly lower odds of VTE than the placebo group $(\mathrm{OR}=0.481,95 \% \mathrm{CI}=0.338-0.685, P<0.001)$ (Fig. 2a; Additional file 1: Table S1).

In Group II (LMWH vs. inhibitor of factor Xa), nine studies, 5 for THR $[20,21,28,30,31]$ and 4 for TKR $[24,25,27,32]$, reported complete total VTE data. Random effects model was considered for THR due to the presence of high heterogeneity for the THR data but low heterogeneity for the TKR data, fixed effect model was used (THR: $Q$ value $=37.097, \quad \mathrm{df}=4, \quad P<0.001, \quad$ I-squared $=$ 89.22\%; TKR: $\mathrm{Q}$ value $=0.906, \mathrm{df}=3, P=0.824$, I-squared $=$ $0 \%)$. The overall effect size showed that LMWH group had higher chance of VTE rate than factor Xa inhibitor group for TKR $(\mathrm{OR}=2.162,95 \% \mathrm{CI}=1.513-3.089, P<0.001)$ but a similar VTE risk for THR $(\mathrm{OR}=2.023,95 \% \mathrm{CI}=0.880$ 4.648, $P=0.097$ ) (Fig. 2b; Additional file 1: Table S1).

For Group III (LMWH vs. direct thrombin inhibitor), five studies had complete total VTE data for THR [23, 34-37] and four for TKR [10, 26, 35, 37]. Because data for both THR and TKR findings was heterogenous across the studies (THR: $\mathrm{Q}$-value $=24.722, \mathrm{df}=4, P<0.001$, I-squared $=83.82 \%$; TKR: $Q$-value $=24.292, \quad \mathrm{df}=3, \quad P<$ 0.001 , I-squared $=87.65 \%$ ), hence random effect models were applied. The overall effect size showed that there was no significant difference between LMWH and direct thrombin inhibitors in the incidence of VTE for either THR $(\mathrm{OR}=1.31,95 \% \mathrm{CI}=0.757-2.267, P=0.335)$ or TKR $(\mathrm{OR}=1.378,95 \% \mathrm{CI}=0.817-2.323, P=0.229) \quad$ (Fig. 2c; Additional file 1: Table S1).

\section{Deep vein thrombosis}

In Group I (LMWH vs. placebo), four studies reported complete total DVT data for THR subjects [20, 29, 38, 39]. A fixed effect model was used as little heterogeneity in the data was observed (THR: $\mathrm{Q}$ value $=4.060, \mathrm{df}=3, P=0.255$, I-squared $=26.11 \%$ ). The overall effect size showed that the LMWH treatment had significantly lower incidence of DVT than placebo group. $(\mathrm{OR}=0.464,95 \% \mathrm{CI}=0.332-$ 0.647, $P<0.001$ ) (Fig. 3a).

In Group II (LMWH vs. inhibitor of factor Xa), ten studies, 5 for THR [20, 21, 28, 30,31] and 5 for TKR) $[22,24,25,27,32]$, had complete data for the rate of DVT. A random effects model was used for both THR and TKR due to the presence of high heterogeneity in the data (THR: $Q$ value $=35.701, \mathrm{df}=4, P<0.001$, I-squared $=88.80 \% ;$ TKR: $Q$ value $=13.523, \mathrm{df}=4, P=$ 0.009 , I-squared $=70.42 \%)$. The overall effect size showed that LMWH group was associated with a higher risk of DVT than factor Xa inhibitors for THR subjects $(\mathrm{OR}=$ 2.351, 95\% CI $=1.040-5.314, P=0.040)$ or $\mathrm{TKR}(\mathrm{OR}=$ 1.827, 95\% CI $=1.352-2.468, P<.001$ ) (Fig. 3b; Additional file 1: Table S1).

For Group III (LMWH vs. direct thrombin inhibitor), three studies reported complete DVT data for THR [23, 36, 37] and three studies reported full data for TKR [10, 26, 37]. A random effect model was used for both THR and TKR analyses as high heterogeneity was observed in the data across studies (THR: Q-value = 13.895, $\mathrm{df}=2, \quad p$-value $=0.001, \quad$ I-squared $=85.61 \%$; TKR: $\mathrm{Q}$-value $=16.857, \quad \mathrm{df}=2, \quad P<0.001, \quad$ I-squared $=88.14 \%)$. The overall effect size showed that there was no significant difference between LMWH and direct thrombin inhibitor 


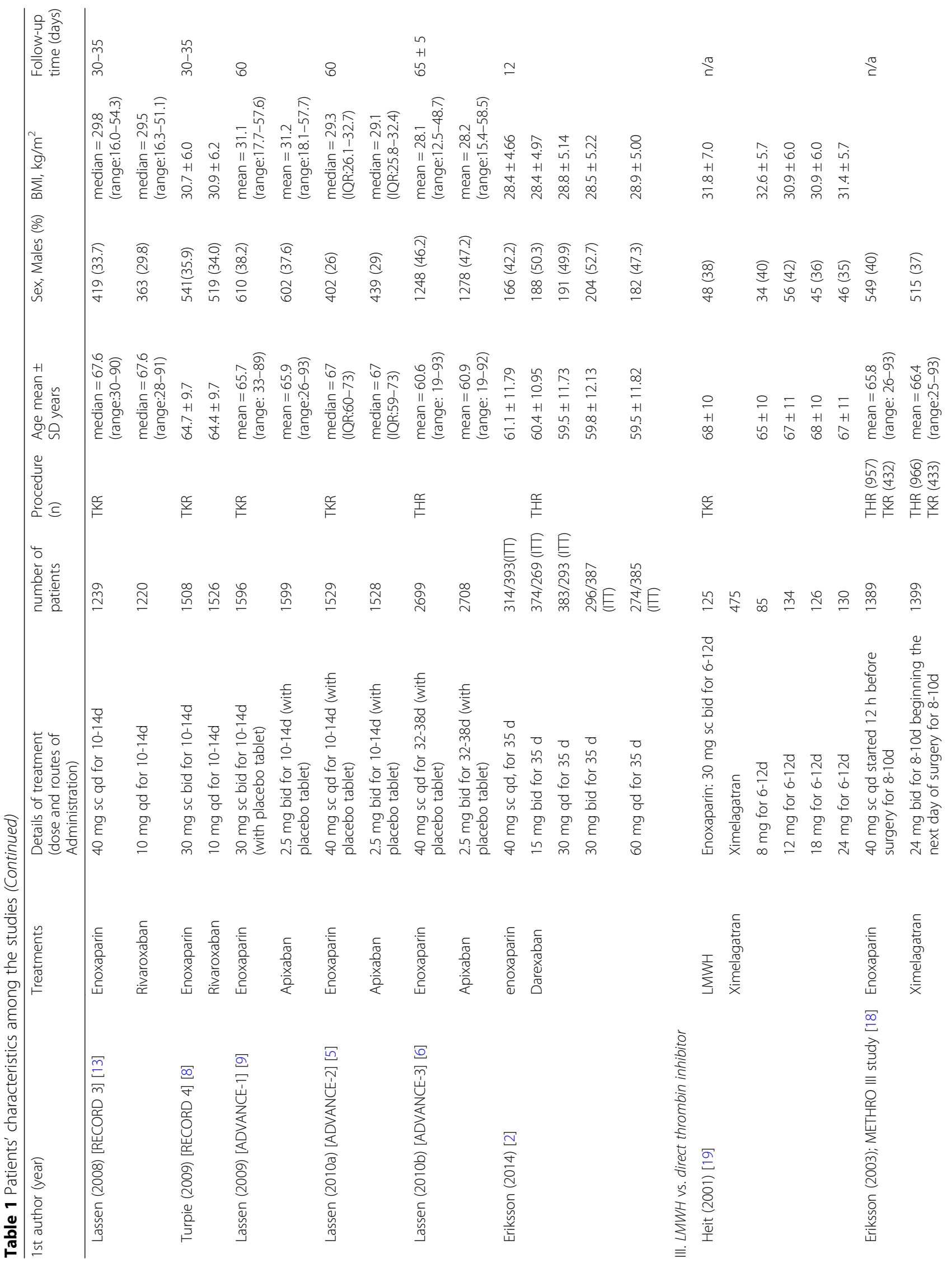




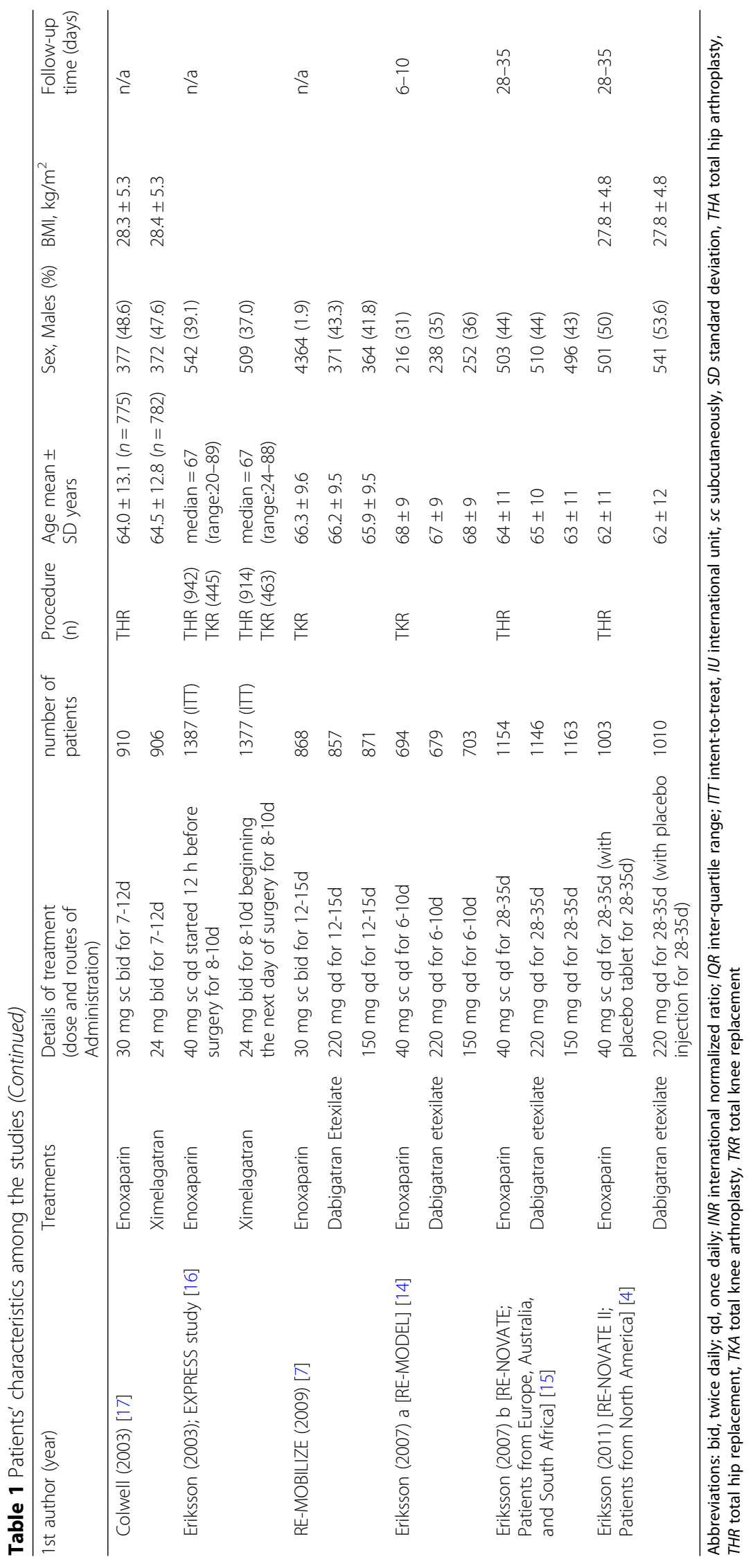




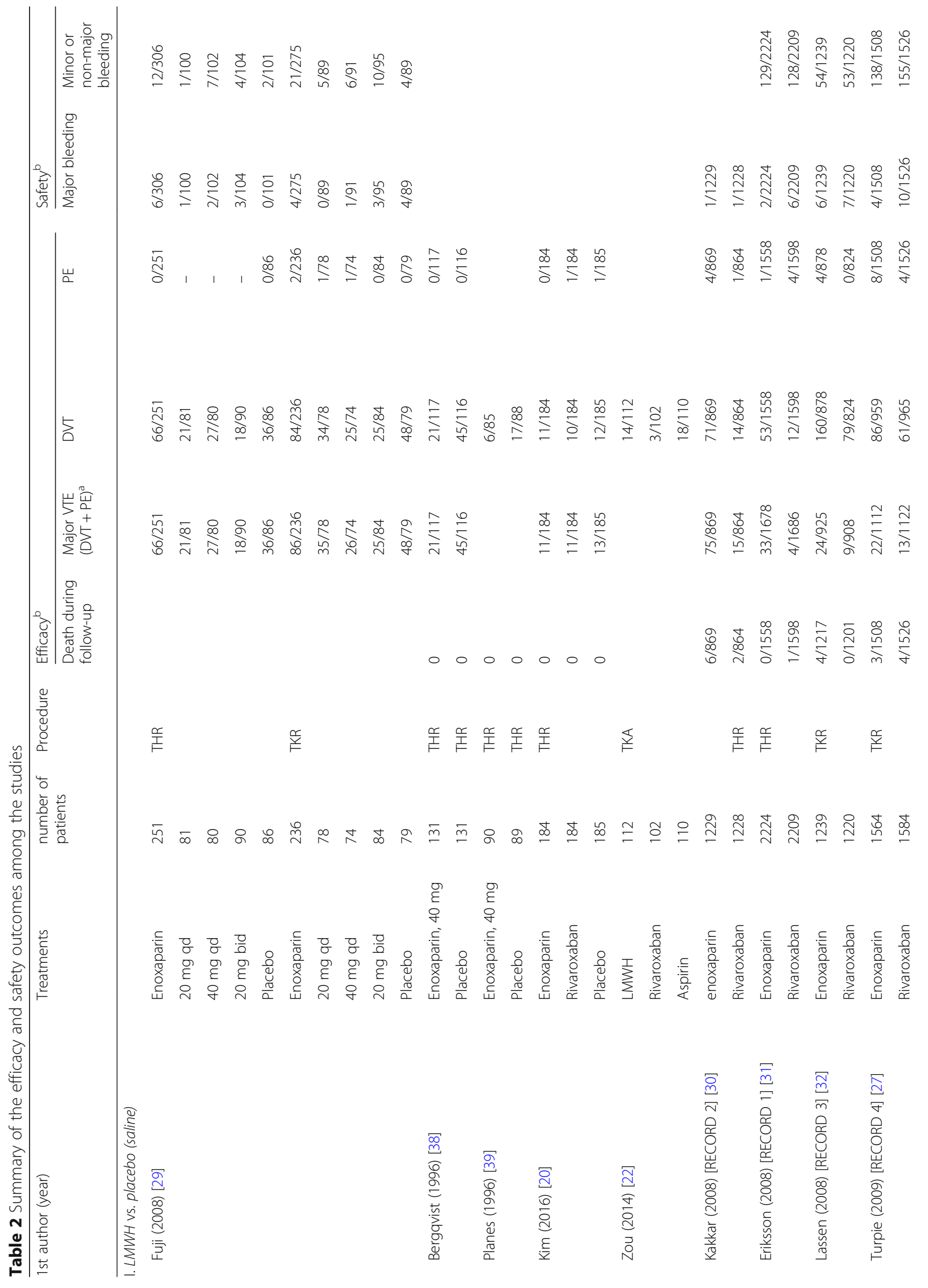




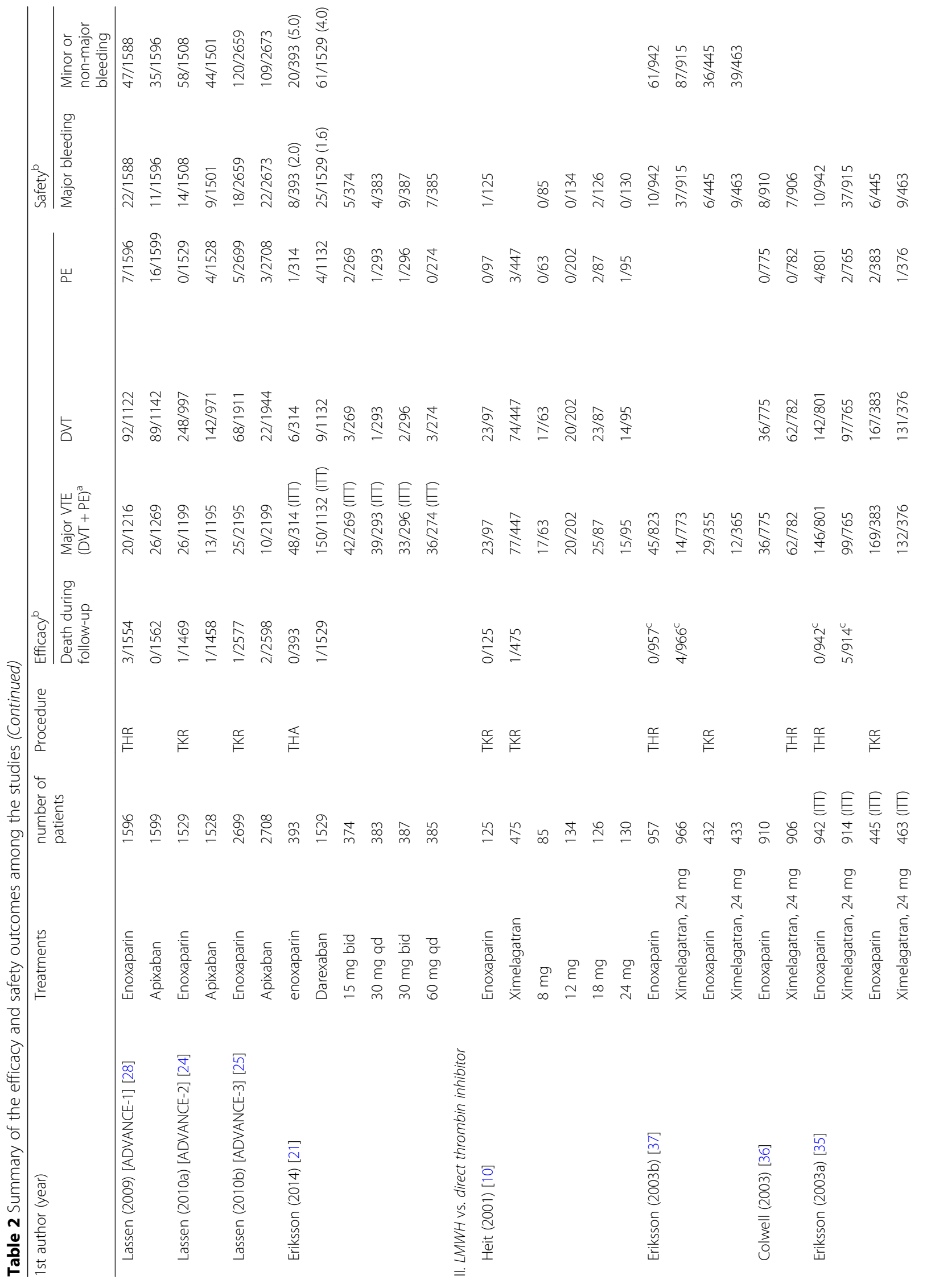




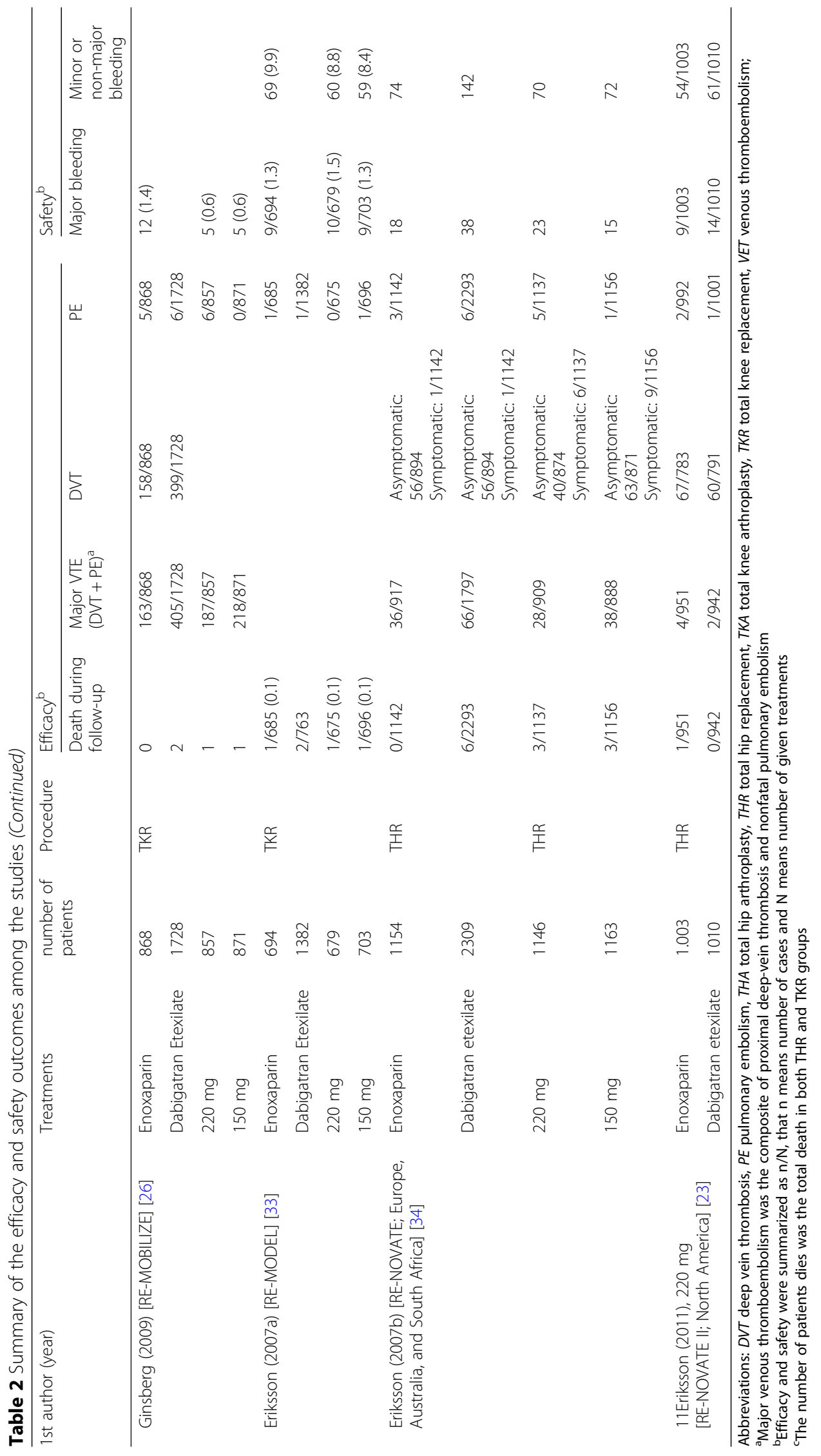


$\mathbf{A}$

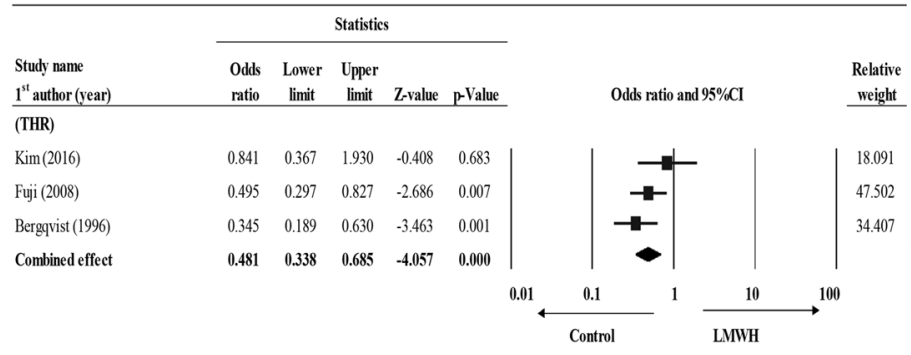

Heterogeneity test.

THR: Q-value $=2.922, \mathrm{~d}=2, \mathrm{p}$-value $=0.232$, I-squared $=31.56 \%$

\section{B}

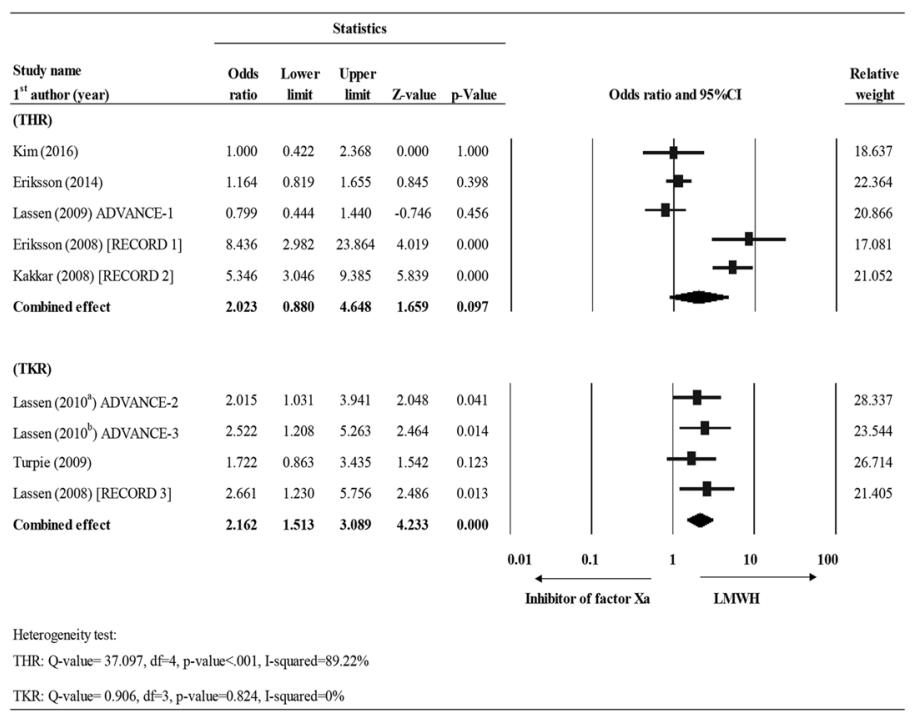

C

\begin{tabular}{|c|c|c|c|c|c|c|c|}
\hline \multirow[b]{2}{*}{$\begin{array}{l}\text { Study name } \\
1^{\text {st author (year) }}\end{array}$} & \multicolumn{5}{|c|}{ Statistics } & \multirow[b]{2}{*}{ Odds ratio and $95 \% \mathrm{CI}$} & \multirow[b]{2}{*}{$\begin{array}{c}\text { Relative } \\
\text { weight }\end{array}$} \\
\hline & $\begin{array}{l}\text { Odds } \\
\text { ratio }\end{array}$ & $\begin{array}{l}\text { Lower } \\
\text { limit }\end{array}$ & $\begin{array}{l}\text { Upper } \\
\text { limit }\end{array}$ & Z-value & $p$-Value & & \\
\hline \multicolumn{8}{|l|}{ (THR) } \\
\hline Eriksson (2011) RE-NOVATE & 1.985 & 0.363 & 10.865 & 0.791 & 0.429 & 1 & 7.520 \\
\hline Eriksson $\left(2007^{b}\right)$ RE-NOVATE & 1.072 & 0.708 & 1.622 & 0.328 & 0.743 & & 23.473 \\
\hline Colwell (2003) & 0.566 & 0.370 & 0.864 & -2.638 & 0.008 & 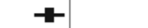 & 23.333 \\
\hline Eriksson $\left(2003^{3}\right)$ & 3.136 & 1.707 & 5.760 & 3.684 & 0.000 & $\rightarrow$ & 20.327 \\
\hline Eriksson $\left(2003^{b}\right)$ & 1.500 & 1.137 & 1.978 & 2.866 & 0.004 & 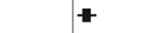 & 25.348 \\
\hline Combined effect & 1.310 & 0.757 & 2.267 & 0.965 & 0.335 & & \\
\hline
\end{tabular}

(TKR)

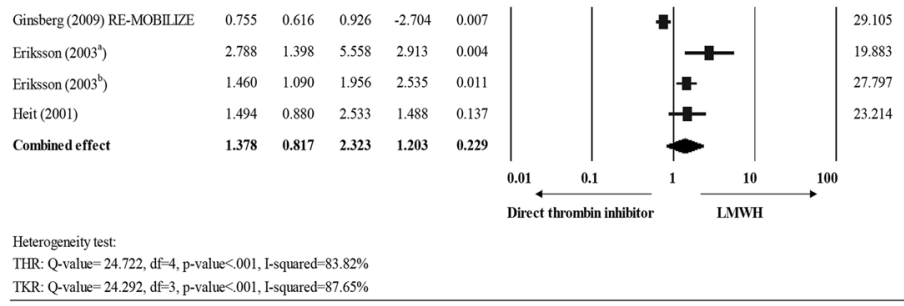

Fig. 2 Forest plot for comparing the total VTE rate between (a) LMWH vs. control (placebo), (b) LMWH vs. inhibitor of factor Xa, and (c) LMWH vs. direct thrombin inhibitor for THR and TKR patients. Abbreviations: Cl, confidence interval; Lower limit, lower bound of the 95\% Cl; Upper limit, upper bound of the $95 \% \mathrm{Cl}$ 


\section{A}

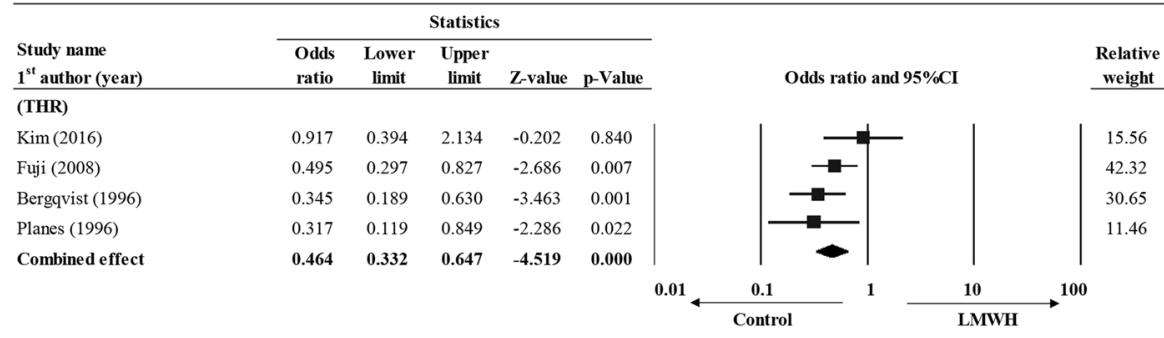

Heterogeneity test:

THR: Q-value $=4.060, \mathrm{df}=3$, p-value $=0.255$, I-squared $=26.11 \%$

B

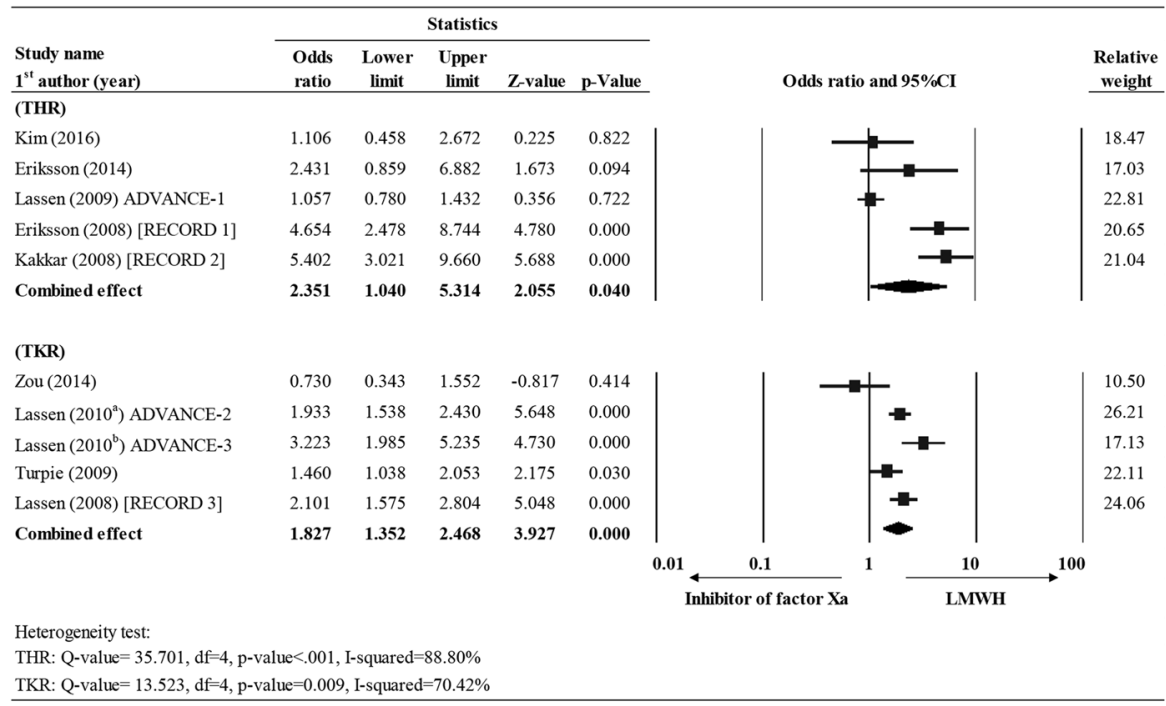

C

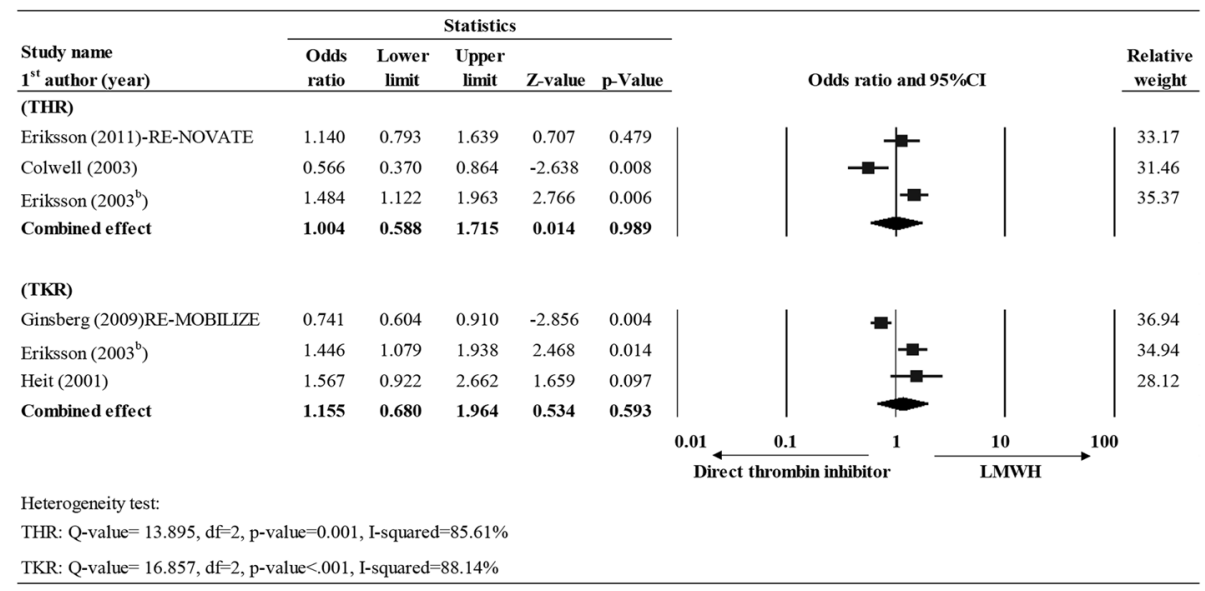

Fig. 3 Forest plot for comparing the total DVT rate between (a) LMWH vs. control (placebo), (b) LMWH vs. inhibitor of factor Xa, and (c) LMWH vs. direct thrombin inhibitor for THR and TKR patients. Abbreviations: Cl, confidence interval; Lower limit, lower bound of the 95\% Cl; Upper limit, upper bound of the $95 \% \mathrm{Cl}$ 
group in the odds of having a DVT for patients undergoing either THR or TKR (THR: OR $=1.004,95 \% \mathrm{CI}=0.588-$ $1.715, \quad p=0.989 ; \quad$ TKR: $\mathrm{OR}=1.155,95 \% \quad \mathrm{CI}=0.680-$ 1.964, $P=0.593$ ) (Fig. 3c; Additional file 1: Table S1).

\section{Pulmonary embolism}

Nine studies in Group II (LMWH vs. inhibitor of factor Xa), five for THR [20, 21, 28, 30,31] and four for TKR $[24,25,27,32]$ reported complete results for PE . Fixed effect model was used as low heterogeneity was observed among the studies for both THR (Q value $=4.155, \mathrm{df}=4$, $P=0.385$, I-squared $=3.74 \%)$ and TKR $(Q$ value $=4.600$, $\mathrm{df}=3, P=0.204$, I-squared $=34.78 \%)$. The overall effect size showed that LMWH and factor Xa inhibitor group were associated with similar likelihood of developing PE for both THR $(\mathrm{OR}=0.554,95 \% \mathrm{CI}=0.272-1.127, P=$ $0.10)$ and TKR. (OR $=1.680,95 \% \mathrm{CI}=0.724-3.896, P=$ 0.227) (Fig. 4a, Additional file 1: Table S1).

Three studies in Group III (LMWH vs. direct thrombin inhibitor) reported PE data for THR [23, 33, 34] and four had PE data for TKR [10, 26, 33, 34]. Low heterogeneity was observed for both THR and TKR (THR: $\mathrm{Q}$-value $=0.440, \mathrm{df}=2, P$ value $=0.802, \mathrm{I}$-squared $=0 \%$; TKR: $Q$-value $=4.600, \mathrm{df}=3, P$ value $=0.204, \mathrm{I}$-squared $=34.78 \%$ ); hence fixed effect model was used for both. The overall effect size showed that LMWH and direct thrombin inhibitor therapies had similar incidence of PE for either THR $(\mathrm{OR}=1.399,95 \% \mathrm{CI}=0.524-3.732, P=$ $0.503)$ or $\mathrm{TKR}(\mathrm{OR}=1.588,95 \% \mathrm{CI}=0.618-4.080, P=$ 0.337) (Fig. 4b; Additional file 1: Table S1).

\section{Major bleeding}

In Group II (LMWH vs. inhibitor of factor Xa), four studies $[21,28,30,31]$ for THR and four studies [24, 25, 27, 32] for TKR reported the incidence of major bleeding. Fixed effect model was used as low heterogeneity was observed for THR (Q value $=4.236, \mathrm{df}=3, P=0.237, \quad$ - -squared $=$ $29.18 \%$ ) and TKR ( $\mathrm{Q}$ value $=3.543, \mathrm{df}=3, P=0.315$, I-squared $=15.33 \%)$. The overall effect size indicated that the chance of major bleeding was similar between types of treatment both for THR and TKR (THR: OR = 1.370, 95\% CI =0.829-2.265, $P=0.219$; TKR: $\mathrm{OR}=0.882$, $95 \% \mathrm{CI}=0.577-1.349, P=0.563$ ) (Fig. 5a; Additional file 1: Table S1).

In Group III (LMWH vs. direct thrombin inhibitor), five studies reported major bleeding data for THR [23, 34-37] and five for TKR [10, 26, 33, 35, 37]. According to the heterogeneity test, random effects and fixed-effect models were applied for both THR and TKR patients, respectively (THR: $\mathrm{Q}$-value $=14.73, \mathrm{df}=4$, $P=0.005$, I-squared $=72.85 \%$; TKR: $Q$-value $=5.202$, $\mathrm{df}=4, P=0.267$, I-squared $=23.11 \%)$. The overall effect size showed that LMWH group was associated with a marginal lower rate of major bleeding than direct thrombin inhibitor for $\mathrm{THR}$ subjects $(\mathrm{OR}=0.524,95 \% \mathrm{CI}=0.277-$ $0.994, P=0.048$ ) but similar likelihood of major bleeding for TKR subjects $(\mathrm{OR}=1.121,95 \% \mathrm{CI}=0.716-1.753$, $p=0.618$ ) (Fig. 5b; Additional file 1: Table S1).

\section{Safety analyses}

a) Major bleeding

Overall incidence of major bleeding events was $1.27 \%$ $[1.06,1.48]$ in this population. In subgroup analysis, Enoxaparin treatment was associated with $1.32 \%$ [1.02, 1.63], Dabigatran 1.25\% [0.68, 1.81], Rivaroxaban 2.02 [1.00, 3.04], Apixaban [0.70 [0.56, 0.84], and Ximelagatran with 0.93 [- 0.06, 1.91] (Additional file 1: Figure S6).

\section{b) Reoperation rate}

Overall reoperation rate was $0.26 \%$ [0.21, 0.31] in these patients. Treatment with Enoxaparin treatment was associated with $0.24 \%$ [0.17, 0.31], with Dabigatran $0.12 \%$ $[0.05,0.19]$, and with Rivaroxaban $0.28 \%$ [0.06, 0.49] reoperation rate (Additional file 1: Figure S7).

\section{c) Mortality}

Overall mortality during treatment was $0.13 \%[0.07$, 0.19]. Mortality rate with Enoxaparin was $0.14 \%$ [0.04, 0.23], with Dabigatran $0.15 \%$ [-0.01, 0.30], and with Rivaroxaban it was $0.19 \%[0.08,0.31]$ (Additional file 1: Figure S8).

\section{d) Other Adverse events}

In this population, $4.31 \%[2.77,5.86]$ patients discontinued treatment due to adverse side effects $(4.57 \%$ $[3.14,6.00]$ with Enoxaparin and 5.53\% [3.41, 7.66] with Dabigatran) (Additional file 1: Figure S9). Adverse reactions during treatment observed by one or more studies included fever, nausea, vomiting, diarrhea, constipation, urinary tract infections, wound infections, wound complications, wound secretion, wound hematoma, joint dislocation, hypotension, insomnia, edema, anemia, dizziness, headache, urinary problems, hemorrhage, blisters, pyrexia, cardiovascular events, myocardial infarction, and stroke.

Overall incidence of cardiovascular events was $0.36 \%$ [0.28, 0.44] (Enoxaparin 0.31\% [0.20, 0.43], Dabigatran $1.05 \%$ [0.95, 1.15], Rivaroxaban 0.24 [-0.04, 0.51], and Apixaban $0.15[0.02,0.28]$ ) (Additional file 1: Figure S10). Overall incidence of stroke in these patients was $0.08 \%$ [0.06, 0.11] (Enoxaparin 0.06\% [0.03, 0.10], Rivaroxaban $0.17 \%$ [0.09, 0.24], and Apixaban 0.04\% [0.01, 0.07]) (Additional file 1: Figure S11). 


\section{A}

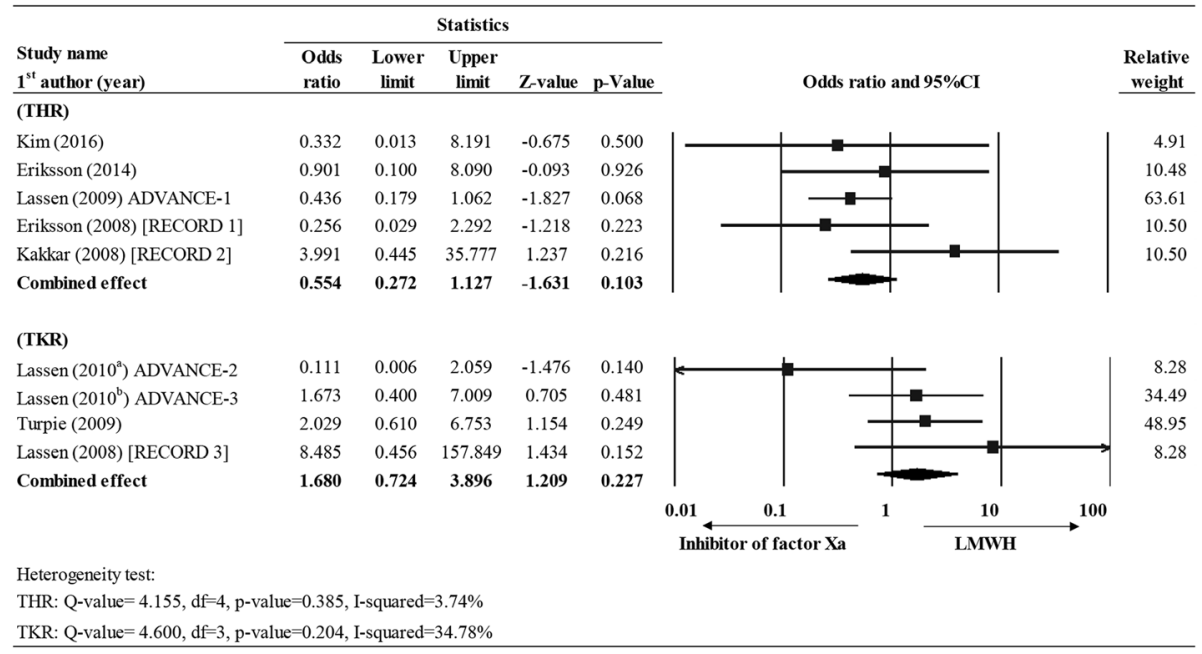

B

\begin{tabular}{|c|c|c|c|c|c|c|c|c|}
\hline \multirow[b]{2}{*}{$\begin{array}{l}\text { Study name } \\
1^{\text {st }} \text { author (year) }\end{array}$} & \multicolumn{5}{|c|}{ Statistics } & & \multirow[b]{2}{*}{ Odds ratio and $95 \% \mathrm{CI}$} & \multirow[b]{2}{*}{$\begin{array}{c}\text { Relative } \\
\text { weight }\end{array}$} \\
\hline & $\begin{array}{l}\text { Odds } \\
\text { ratio }\end{array}$ & $\begin{array}{c}\text { Lower } \\
\text { limit }\end{array}$ & $\begin{array}{c}\text { Upper } \\
\text { limit }\end{array}$ & Z-value & p-Value & & & \\
\hline \multicolumn{9}{|l|}{ (THR) } \\
\hline Eriksson (2011) RE-NOVATE & 2.020 & 0.183 & 22.315 & 0.574 & 0.566 & & 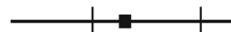 & 16.69 \\
\hline Eriksson $\left(2007^{b}\right)$ RE-NOVATE & 1.004 & 0.251 & 4.022 & 0.006 & 0.996 & & & 50.00 \\
\hline Eriksson $\left(2003^{b}\right)$ & 1.915 & 0.350 & 10.484 & 0.749 & 0.454 & & & 33.31 \\
\hline Combined effect & 1.399 & 0.524 & 3.732 & 0.670 & 0.503 & & & \\
\hline \multicolumn{9}{|l|}{ (TKR) } \\
\hline Ginsberg (2009) RE-MOBILIZE & 1.663 & 0.506 & 5.464 & 0.838 & 0.402 & & & 62.93 \\
\hline Eriksson $\left(2007^{a}\right)$ RE-MODEL & 2.019 & 0.126 & 32.328 & 0.497 & 0.620 & & & 11.58 \\
\hline Eriksson $\left(2003^{\mathrm{b}}\right)$ & 1.969 & 0.178 & 21.801 & 0.552 & 0.581 & & & 15.40 \\
\hline Heit (2001) & 0.651 & 0.033 & 12.711 & -0.283 & 0.777 & & & 10.09 \\
\hline \multirow[t]{3}{*}{ Combined effect } & 1.588 & 0.618 & 4.080 & 0.960 & 0.337 & & & \\
\hline & & & & & & 0.01 & 10 & \\
\hline & & & & & & Direct thrombin & a inhibitor & \\
\hline \multicolumn{9}{|l|}{ Heterogeneity test: } \\
\hline \multicolumn{9}{|c|}{ THR: Q-value $=0.440, \mathrm{df}=2, \mathrm{p}$-value $=0.802, \mathrm{I}$-squared $=0 \%$} \\
\hline \multicolumn{9}{|c|}{ TKR: Q-value $=4.600, \mathrm{df}=3, \mathrm{p}$-value $=0.204, \mathrm{I}$-squared $=34.78 \%$} \\
\hline
\end{tabular}

Fig. 4 Forest plot for comparing the PE rate between (a) LMWH vs. control (placebo), (b) LMWH vs. inhibitor of factor Xa, and (c) LMWH vs. direct thrombin inhibitor for THR and TKR patients. Abbreviations: Cl, confidence interval; Lower limit, lower bound of the 95\% Cl; Upper limit, upper bound of the $95 \% \mathrm{Cl}$

\section{Sensitivity analysis}

Sensitivity analyses were performed using a leave-one-out approach in which a meta-analysis for total VET (Additional file 1: Figure S1), total DVT (Additional file 1: Figure S2), PE (Additional file 1: Figure S3) and major bleeding (Additional file 1: Figure S4) were performed in which each study for a given analysis was left out in turn. The direction and magnitude of the combined estimates did not markedly differ with the removal of a single study, indicating that the meta-analysis had good reliability and that the data was not overly influenced by any study.

\section{Quality assessment}

The results of quality assessment are shown in Additional file 1: Figure S5. In this figure, Panel A shows the potential risk of bias in an individual study, and Panel B shows the summary of bias for included studies. The most potential risk of bias came from attrition bias and selective reporting bias. Also, several studies failed to clearly indicate if they used an intent-to-treat in analysis. Overall, the included studies are of good quality.

\section{Discussion}

Anticoagulants are routinely used to prevent deep vein thrombosis following TKR and THR to prevent DVT. However, the relative effectiveness of LMWH and other anticoagulants therapies in patients at risk for DVT has not been comprehensively studied. In the present study, the comparison of LMWH with placebo found that LMWH was associated with lower odds of VTE and DVT compared to placebo in THR subjects, suggesting 


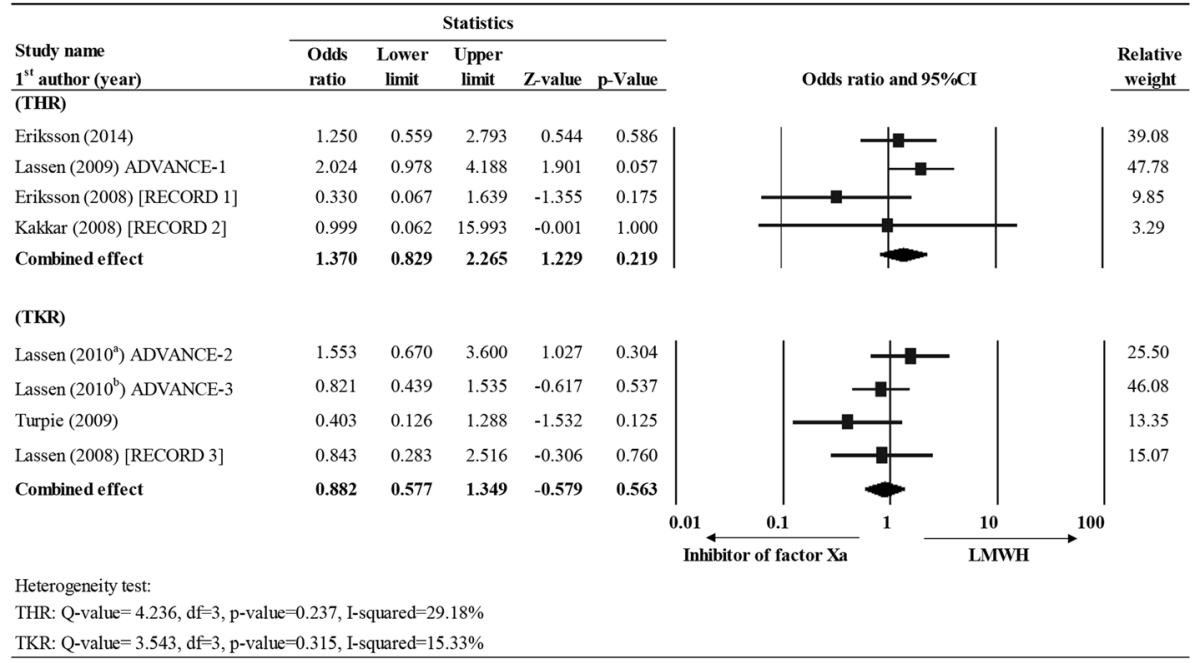

B

\begin{tabular}{|c|c|c|c|c|c|c|c|}
\hline \multirow[b]{2}{*}{$\begin{array}{l}\text { Study name } \\
1^{\text {st author (year) }}\end{array}$} & \multicolumn{5}{|c|}{ Statistics } & \multirow{3}{*}{ Odds ratio and $95 \% \mathrm{CI}$} & \multirow{3}{*}{$\begin{array}{r}\text { Relative } \\
\text { weight }\end{array}$} \\
\hline & $\begin{array}{l}\text { Odds } \\
\text { ratio }\end{array}$ & $\begin{array}{c}\text { Lower } \\
\text { limit }\end{array}$ & $\begin{array}{c}\text { Upper } \\
\text { limit }\end{array}$ & Z-value & p-Value & & \\
\hline (THR) & & & & & & & \\
\hline Eriksson (2011)-RE-NOVATE & 0.644 & 0.278 & 1.495 & -1.024 & 0.306 & & 18.85 \\
\hline Eriksson $\left(2007^{\mathrm{b}}\right)$ RE-NOVATE & 0.947 & 0.538 & 1.667 & -0.189 & 0.850 & & 22.98 \\
\hline Colwell (2003) & 1.139 & 0.411 & 3.154 & 0.251 & 0.802 & & 16.37 \\
\hline Eriksson $\left(2003^{\mathrm{a}}\right)$ & 0.255 & 0.126 & 0.515 & -3.805 & 0.000 & & 20.90 \\
\hline Eriksson $\left(2003^{b}\right)$ & 0.255 & 0.126 & 0.515 & -3.805 & 0.000 & & 20.90 \\
\hline Combined effect & 0.524 & 0.277 & 0.994 & -1.979 & 0.048 & & \\
\hline
\end{tabular}

(TKR)

Ginsberg (2009) RE-MOBILI7E

Eriksson $\left(2007^{\mathrm{a}}\right)$ RE-MODEL

Eriksson $\left(2003^{\mathrm{a}}\right)$

Eriksson $\left(2003^{\mathrm{b}}\right)$

Heit (2001)

Combined effect

$\begin{array}{rrrrr}2.408 & 1.036 & 5.597 & 2.043 & 0.041 \\ 0.943 & 0.424 & 2.094 & -0.145 & 0.884 \\ 0.689 & 0.243 & 1.953 & -0.700 & 0.484 \\ 0.689 & 0.243 & 1.953 & -0.700 & 0.484 \\ 1.907 & 0.172 & 21.205 & 0.525 & 0.599 \\ \mathbf{1 . 1 2 1} & \mathbf{0 . 7 1 6} & \mathbf{1 . 7 5 3} & \mathbf{0 . 4 9 9} & \mathbf{0 . 6 1 8}\end{array}$

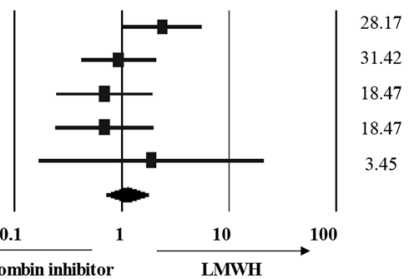

Heterogeneity test:

THR: Q-value $=14.734, \mathrm{df}=4, \mathrm{p}$-value $=0.005$, I-squared $=72.85 \%$

TKR: $\mathrm{Q}$-value $=5.202, \mathrm{df}=4, \mathrm{p}$-value $=0.267, \mathrm{I}$-squared $=23.11 \%$

Fig. 5 Forest plot for comparing the major bleeding rate between LMWH vs. (a) LMWH vs. inhibitor of factor Xa and (b) LMWH vs. direct thrombin inhibitor for THR and TKR patients. Abbreviations: Cl, confidence interval; Lower limit, lower bound of the 95\% Cl; Upper limit, upper bound of the $95 \% \mathrm{Cl}$

that prophylactic treatment of patients with LMWH could significantly reduce the rate of VTE and DVT but the incidence of PE was similar between the two groups. Compared to factor Xa inhibitors (e.g. rivaroxaban, apixaban, darexaban), LMWH was associated with higher incidence of VTE in TKR subjects, but the odds of VTE was similar between treatment groups in THR subjects. LMWH was associated with higher likelihood of DVT in patients with either THR or TKR, suggesting that factor Xa inhibitors might be superior to LMWH in reducing the rate of VTE and DVT. However, both prophylactic treatments showed a similar chance of pulmonary embolism and major bleeding in patients with THR and TKR. The odds of VTE, DVT, PE were similar between LMWH and direct thrombin inhibitors (e.g. ximelagatran, dabigatran etexilate); although a marginal benefit in preventing major bleeding was observed for LMWH compared with direct thrombin therapies in patients with THR $(P=0.048)$. These results indicate that LMWH is an effective prophylactic agent for reducing VTE when it was compared with patients without prophylactic treatment. However, LMWH might be less effective than factor Xa inhibitors in reducing the risk of thromboembolic 
events. In general, LMWH showed effectiveness similar to direct thrombin inhibitors in reducing the risk of thromboembolic events as well as major bleeding.

The RCTs for comparing LMWH with placebo in THR or TKR subjects are rare in recent years. A prior systematic review by Hull et al. [40] assessed LMWH in comparison with placebo for the prevention of thrombosis in an out-patient setting in selective hip surgery subjects [40]. They found that compared to placebo, LMWH was associated with decreased episodes of DVT, proximal venous thrombosis, and symptomatic venous thrombosis. These findings support the extended out-of-hospital use of LMWH following hip surgery. A prior meta-analysis by Tasker et al. [41] assessed the in-patient clinical outcomes of LMWH compared to placebo in patients who had THR [41]. They found no difference between LMWH and placebo in affecting the risk of pulmonary embolism, other deaths, all-cause mortality, or major bleeding. They found that compared with placebo, LMWH reduced non-fatal $\mathrm{PE}$ at the expense of hematoma formation. Although, our study also assessed in-patient outcomes, it is difficult to compare our findings directly with those of Tasker et al. as we did not evaluate the relative effectiveness of LMWH and placebo with PE or major bleeding due to the limited number of studies reporting these outcomes.

Several systematic reviews and meta-analyses have evaluated the use of different anticoagulant therapies in TKR and THR subjects (see Additional file 1: Table S2) $[8,14,42-56]$. Consistent with the current study, the prior meta-analyses found that the factor Xa inhibitors, rivaroxaban and apixaban, have better anticoagulant effect as compared with the LMWH enoxaparin [42-44]. In contrast to our findings, the prior studies found enoxaparin had a higher incidence of major bleeding compared with some, but not all, of the factor Xa inhibitors. For example, the study of Gomez-Outes et al. [44] found that compared to enoxaparin, the relative risk of clinically relevant bleeding was higher with rivaroxaban, similar with dabigatran, and lower with apixaban. Gomez-Outes et al. concluded that the higher efficacy observed with the factor Xa inhibitors was generally associated with higher bleeding tendency than with LMWH [44]. The meta-analysis of Feng et al. [43] also found that rivaroxaban was associated with a higher bleeding rate [43]. In this meta-analysis, only those RCTs were included which compared the efficacy and safety of any oral direct factor Xa inhibitor with that of enoxaparin for elective THA or TKA. The oral direct factor $\mathrm{Xa}$ inhibitor included rivaroxaban, apixaban, darexaban, betrixaban, edoxaban and several developing drugs (e.g. BAY 59-7939, YM150, LY517717). In addition, several trials were open-label and therefore allocation concealment bias may have existed. The author also found that rivaroxaban had a higher bleeding rate, while apixaban and edoxaban did not show significantly higher bleeding risks [43].
Three previous meta-analyses compared the effectiveness of different direct thrombin inhibitors with enoxaparin $[14,45,46]$. In general, our results are similar to those of a few earlier studies which found that dabigatran was similar to enoxaparin with respect to VTE incidence. The same studies also found that the risk of major bleeding was similar between treatments. The meta-analysis of Cohen et al. found that ximelagatran had a significantly lower rate of VTE than with enoxaparin with no difference in bleeding rates [46]. Although, our meta-analysis did not assess individual direct thrombin inhibitors and so the findings are difficult to compare with the prior analyses, we did observe a potentially lower rate of major bleeding associated with LWMH.

The present study has several limitations that should be considered. In addition, the dosing regimens for the different therapies differed across studies. For example, three different regimens of enoxaparin $(40 \mathrm{mg}$ once daily or $20 \mathrm{mg}$ or $30 \mathrm{mg}$ bid) were used. A previous meta-analysis compared two different regimens of enoxaparin to oral anticoagulants (apixaban, dabigatran, and rivaroxaban) as thromboprophylaxis in elective TKR or THR [57]. An adjusted indirect comparison showed that bid $40 \mathrm{mg}$ enoxaparin was significantly less effective than $30 \mathrm{mg}$ bid in preventing VTE (relative risk 0.71, $P<0.001$ ). The authors concluded that the use of once-daily $40 \mathrm{mg}$ enoxaparin regimen as a control in clinical trials would lead to more favorable estimates of relative efficacy for the new oral anticoagulants than if enoxaparin $30 \mathrm{mg}$ bid had been chosen as a comparator. Our study was able to assess the use of the different drugs in an in-patient setting only. It would be of interest to perform a similar analysis evaluating the long-term use to these therapies in an out-patient setting.

\section{Conclusions}

This meta-analysis is the first to our knowledge to evaluate the overall relative effectiveness of LMWH by comparing with placebo control and two major classes of anticoagulants therapy (i.e., factor Xa inhibitors and direct thrombin inhibitor) to treat patient who had TKR or THR surgeries. The findings indicate that prophylactic treatment of patients with LMWH could significantly reduce the rate of VTE and DVT. However, the factor Xa inhibitors might have better anticoagulant effect as compared with the LMWH enoxaparin. Compared to direct thrombin inhibitors, LMWH have similar incidence of VTE, DVT and PE but lower incidence of major bleeding in THR or TKR subjects. In general, LMWH has similar effectiveness to factor Xa inhibitor and direct thrombin inhibitors with respect to clinical outcomes associated with anticoagulation therapy. Factor Xa inhibitors, such as rivaroxaban, is superior to enoxaparin in reducing symptomatic VTE but the trade-offs between thromboprophylaxis versus increased major bleeding should be considered. 


\section{Key messages}

- In comparison with patients without prophylaxis, low molecular weight heparin (LMWH) effectively reduces venous thromboembolism (VTE) and deep vein thrombosis (DVT) after total hip replacement (TKR).

- Compared to factor Xa inhibitors, LMWH may have higher incidence of VTE and DVT but similar rates of pulmonary embolism and major bleeding in THR or TKR subjects.

- In comparison with direct thrombin inhibitors, LMWH have similar incidence of VTE, DVT and pulmonary embolism but lower incidence of major bleeding in THR or TKR subjects.

\section{Additional file}

Additional file 1: Figure S1. Sensitivity analysis using the leave-one-out approach of the influence of each study on the pooled estimate for comparing total VTE rate between LMWH vs. control (A) placebo, (B) inhibitor of factor $\mathrm{Xa}$, and $(\mathrm{C})$ direct thrombin inhibitor for THR and TKR patients. Abbreviations: Cl, confidence interval; Lower limit, lower bound of the $95 \% \mathrm{Cl}$; Upper limit, upper bound of the $95 \% \mathrm{Cl}$. Figure S2. Sensitivity analysis using the leave-one-out approach of the influence of each study on the pooled estimate for comparing total DVT rate between LMWH vs. control (A) placebo, (B) inhibitor of factor $\mathrm{Xa}$, and (C) direct thrombin inhibitor for THR and TKR patients. Abbreviations: $\mathrm{Cl}$, confidence interval; Lower limit, lower bound of the 95\% Cl; Upper limit, upper bound of the $95 \% \mathrm{Cl}$. Figure S3. Sensitivity analysis using the leave-one-out approach of the influence of each study on the pooled estimate for comparing PE rate between LMWH vs. control (A) inhibitor of factor $\mathrm{Xa}$, and (B) direct thrombin inhibitor for THR and TKR patients. Abbreviations: Cl, confidence interval; Lower limit, lower bound of the 95\% Cl; Upper limit, upper bound of the $95 \% \mathrm{Cl}$. Figure S4. Sensitivity analysis using the leaveone-out approach of the influence of each study on the pooled estimate for comparing major bleeding rate $(\mathrm{A})$ inhibitor of factor $\mathrm{Xa}$, and $(\mathrm{B})$ direct thrombin inhibitor for THR and TKR patients. Abbreviations: $\mathrm{Cl}$, confidence interval; Lower limit, lower bound of the 95\% Cl; Upper limit, upper bound of the $95 \% \mathrm{Cl}$. Figure $\mathbf{S} 5$. The results of quality assessment for (A) individual studies, and (B) the summary of bias for all included studies. Figure S6. Forest graph showing the incidence of major bleeding events. Figure S7. Forest graph showing reoperation rate in this population. Figure S8. Forest graph showing the immortality rate in this population. Figure S9. Forest graph showing the percentage of patients who discontinued treatment due to adverse reaction. Figure S10. Forest graph showing the incidence of cardiovascular events. Figure S11. Forest graph showing the incidence of stroke. Table S1. Summary of meta-analysis results. Table S2. Published systematic review and meta-analysis relating to thromboprophylasis after THR and TKR (DOCX $734 \mathrm{~kb})$

\section{Abbreviations}

AAOS: American Association of Orthopedic Surgeons; ACCP: American College of Chest Physicians; DVT: deep vein thrombosis; MWH: lowmolecular-weight heparin; RCTs: randomized controlled studies; THR: total hip replacement; TKR: received total knee; VTE: venous thromboembolism

\section{Availability of data and materials}

All data generated or analyzed during this study are included in this published article.

\section{Authors' contributions}

We declare that this work was done by the authors named in this article and all liabilities pertaining to claims relating to the content of this article will be borne by the authors. $\mathrm{XL}$ and $J \mathrm{~L}$ designed the study and revised the paper.
$\mathrm{XL}$ and $J \mathrm{~L}$ collected data and carried out the analysis, and $J \mathrm{~L}$ wrote the paper. Both authors read and approved the final manuscript.

Ethics approval and consent to participate

Not applicable.

Consent for publication

Not applicable.

\section{Competing interests}

The authors declare that they have no competing interests, and all authors should confirm its accuracy.

\section{Publisher's Note}

Springer Nature remains neutral with regard to jurisdictional claims in published maps and institutional affiliations.

Received: 1 May 2018 Accepted: 1 August 2018

Published online: 08 September 2018

\section{References}

1. Chapelle C, Rosencher N, Jacques Zufferey P, Mismetti P, Cucherat M, Laporte S. Prevention of venous thromboembolic events with lowmolecular-weight heparin in the non-major orthopaedic setting: metaanalysis of randomized controlled trials. Arthroscopy. 2014;30:987-96.

2. Falck-Ytter Y, Francis CW, Johanson NA, Curley C, Dahl OE, Schulman S, et al. Prevention of VTE in orthopedic surgery patients: antithrombotic therapy and prevention of thrombosis, 9th ed: American College of Chest Physicians Evidence-Based Clinical Practice Guidelines. Chest. 2012;141:e278S-325S.

3. Thorlund JB, Juhl CB, Roos EM, Lohmander LS. Arthroscopic surgery for degenerative knee: systematic review and meta-analysis of benefits and harms. BMJ. 2015:350:h2747.

4. Yeo KS, Lim WS, Lee YH. Deep vein thrombosis in arthroscopic surgery and chemoprophylaxis recommendation in an Asian population. Singap Med J. 2016;57:452-5

5. Sobieraj DM, Coleman Cl, Tongbram V, Lee S, Colby J, Chen WT, et al. Venous thromboembolism in orthopedic surgery. Comparative effectiveness review no. 49. AHRQ publication no. 12-EHC020-EF. Rockville: Agency for Healthcare Research and Quality; 2012. www.effectivehealthcare.ahrq.gov/ reports/final.cfm. Accessed 19 Sept 2017.

6. Eikelboom JW, Quinlan DJ, O'Donnell M. Major bleeding, mortality, and effi cacy of fondaparinux in venous thromboembolism prevention trials. Circulation. 2009:120:2006-11.

7. Adam SS, McDuffie JR, Lachiewicz PF, Ortel TL, Williams JW Jr. Comparative effectiveness of new oral anticoagulants and standard thromboprophylaxis in patients having total hip or knee replacement: a systematic review. Ann Intern Med. 2013;159:275-84.

8. Kwong LM. Therapeutic potential of rivaroxaban in the prevention of venous thromboembolism following hip and knee replacement surgery: a review of clinical trial data. Vasc Health Risk Manag. 2011;7:461-6.

9. Hirsh J, Levine MN. Low molecular weight heparin: laboratory properties and clinical evaluation. A review Eur J Surg Suppl. 1994:9-22.

10. Heit JA, Colwell CW, Francis CW, Ginsberg JS, Berkowitz SD, Whipple J, et al. Comparison of the oral direct thrombin inhibitor ximelagatran with enoxaparin as prophylaxis against venous thromboembolism after total knee replacement: a phase 2 dose-finding study. Arch Intern Med. 2001;161:2215-21.

11. Wilke T, Muller S. Nonadherence in outpatient thromboprophylaxis after major orthopedic surgery: a systematic review. Expert Rev Pharmacoecon Outcomes Res. 2010;10:691-700.

12. Weitz JI. Low-molecular-weight heparins. N Engl J Med. 1997;337:688-98.

13. Sun Y, Chen D, Xu Z, Shi D, Dai J, Qin J, et al. Deep venous thrombosis after knee arthroscopy: a systematic review and meta-analysis. Arthroscopy. 2014;30:406-12

14. Huisman MV, Quinlan DJ, Dahl OE, Schulman S. Enoxaparin versus dabigatran or rivaroxaban for thromboprophylaxis after hip or knee arthroplasty: results of separate pooled analyses of phase III multicenter randomized trials. Circ Cardiovasc Qual Outcomes. 2010;3:652-60.

15. Hayden JA, van der Windt DA, Cartwright $J \mathrm{~L}$, Cote P, Bombardier C. Assessing bias in studies of prognostic factors. Ann Intern Med. 2013;158:280-6. 
16. Higgins JP, Altman DG, Gotzsche PC, Juni P, Moher D, Oxman AD, et al. The Cochrane Collaboration's tool for assessing risk of bias in randomised trials. BMJ. 2011;343:d5928.

17. Hardy RJ, Thompson SG. Detecting and describing heterogeneity in metaanalysis. Stat Med. 1998;17:841-56.

18. Takkouche B, Cadarso-Suarez C, Spiegelman D. Evaluation of old and new tests of heterogeneity in epidemiologic meta-analysis. Am J Epidemiol. 1999;150:206-15.

19. Sterne JA, Sutton AJ, loannidis JP, Terrin N, Jones DR, Lau J, et al. Recommendations for examining and interpreting funnel plot asymmetry in meta-analyses of randomised controlled trials. BMJ. 2011;343:d4002.

20. Kim SM, Moon YW, Lim SJ, Kim DW, Park YS. Effect of oral factor Xa inhibitor and low-molecular-weight heparin on surgical complications following total hip arthroplasty. Thromb Haemost. 2016;115:600-7.

21. Eriksson Bl, Agnelli G, Gallus AS, Lassen MR, Prins MH, Renfurm RW, et al. Darexaban (YM150) versus enoxaparin for the prevention of venous thromboembolism after total hip arthroplasty: a randomised phase Ilb dose confirmation study (ONYX-3). Thromb Haemost. 2014;111:213-25.

22. Zou Y, Tian S, Wang Y, Sun K. Administering aspirin, rivaroxaban and lowmolecular-weight heparin to prevent deep venous thrombosis after total knee arthroplasty. Blood Coagul Fibrinolysis. 2014;25:660-4

23. Eriksson BI, Dahl OE, Huo MH, Kurth AA, Hantel S, Hermansson K, et al. Oral dabigatran versus enoxaparin for thromboprophylaxis after primary total hip arthroplasty (RE-NOVATE $\|^{*}$ ). A randomised, double-blind, non-inferiority trial. Thromb Haemost. 2011;105:721-9.

24. Lassen MR, Raskob GE, Gallus A, Pineo G, Chen D, Hornick P. Apixaban versus enoxaparin for thromboprophylaxis after knee replacement (ADVANCE-2): a randomised double-blind trial. Lancet. 2010;375:807-15.

25. Lassen MR, Gallus A, Raskob GE, Pineo G, Chen D, Ramirez LM. Apixaban versus enoxaparin for thromboprophylaxis after hip replacement. N Engl J Med. 2010;363:2487-98.

26. Ginsberg JS, Davidson BL, Comp PC, Francis CW, Friedman RJ, Huo MH, et al. Oral thrombin inhibitor dabigatran etexilate vs north American enoxaparin regimen for prevention of venous thromboembolism after knee arthroplasty surgery. J Arthroplast. 2009;24:1-9.

27. Turpie AG, Lassen MR, Davidson BL, Bauer KA, Gent M, Kwong LM, et al. Rivaroxaban versus enoxaparin for thromboprophylaxis after total knee arthroplasty (RECORD4): a randomised trial. Lancet. 2009;373:1673-80.

28. Lassen MR, Raskob GE, Gallus A, Pineo G, Chen D, Portman RJ. Apixaban or enoxaparin for thromboprophylaxis after knee replacement. N Engl J Med. 2009;361:594-604

29. Fuji T, Ochi T, Niwa S, Fujita S. Prevention of postoperative venous thromboembolism in Japanese patients undergoing total hip or knee arthroplasty: two randomized, double-blind, placebo-controlled studies with three dosage regimens of enoxaparin. J Orthop Sci. 2008;13:442-51.

30. Kakkar AK, Brenner B, Dahl OE, Eriksson Bl, Mouret P, Muntz J, et al. Extended duration rivaroxaban versus short-term enoxaparin for the prevention of venous thromboembolism after total hip arthroplasty: a double-blind, randomised controlled trial. Lancet. 2008:372:31-9.

31. Eriksson Bl, Borris LC, Friedman RJ, Haas S, Huisman MV, Kakkar AK, et al. Rivaroxaban versus enoxaparin for thromboprophylaxis after hip arthroplasty. N Engl J Med. 2008;358:2765-75.

32. Lassen MR, Ageno W, Borris LC, Lieberman JR, Rosencher N, Bandel TJ, et al. Rivaroxaban versus enoxaparin for thromboprophylaxis after total knee arthroplasty. N Engl J Med. 2008;358:2776-86.

33. Eriksson Bl, Dahl OE, Rosencher N, Kurth AA, van Dijk CN, Frostick SP, et al. Oral dabigatran etexilate vs. subcutaneous enoxaparin for the prevention of venous thromboembolism after total knee replacement: the RE-MODEL randomized trial. J Thromb Haemost. 2007:5:2178-85.

34. Eriksson BI, Dahl OE, Rosencher N, Kurth AA, van Dijk CN, Frostick SP, et al. Dabigatran etexilate versus enoxaparin for prevention of venous thromboembolism after total hip replacement: a randomised, double-blind, non-inferiority trial. Lancet. 2007;370:949-56.

35. Eriksson Bl, Agnelli G, Cohen AT, Dahl OE, Lassen MR, Mouret P, et al. The direct thrombin inhibitor melagatran followed by oral ximelagatran compared with enoxaparin for the prevention of venous thromboembolism after total hip or knee replacement: the EXPRESS study. J Thromb Haemost. 2003;1:2490-6.

36. Colwell CW Jr, Berkowitz SD, Davidson BL, Lotke PA, Ginsberg JS, Lieberman $J R$, et al. Comparison of ximelagatran, an oral direct thrombin inhibitor, with enoxaparin for the prevention of venous thromboembolism following total hip replacement. A randomized, double-blind study. J Thromb Haemost. 2003;1:2119-30.

37. Eriksson Bl, Agnelli G, Cohen AT, Dahl OE, Mouret P, Rosencher N, et al. Direct thrombin inhibitor melagatran followed by oral ximelagatran in comparison with enoxaparin for prevention of venous thromboembolism after total hip or knee replacement. Thromb Haemost. 2003:89:288-96.

38. Bergqvist D, Benoni G, Bjorgell O, Fredin H, Hedlundh U, Nicolas S, et al. Lowmolecular-weight heparin (enoxaparin) as prophylaxis against venous thromboembolism after total hip replacement. N Engl J Med. 1996;335:696-700.

39. Planes A, Vochelle N, Darmon JY, Fagola M, Bellaud M, Huet Y. Risk of deepvenous thrombosis after hospital discharge in patients having undergone total hip replacement: double-blind randomised comparison of enoxaparin versus placebo. Lancet. 1996:348:224-8.

40. Hull RD, Pineo GF, Stein PD, Mah AF, Maclsaac SM, Dahl OE, et al. Extended out-of-hospital low-molecular-weight heparin prophylaxis against deep venous thrombosis in patients after elective hip arthroplasty: a systematic review. Ann Intern Med. 2001:135:858-69.

41. Tasker A, Harbord R, Bannister GC. Meta-analysis of low molecular weight heparin versus placebo in patients undergoing total hip replacement and post-operative morbidity and mortality since their introduction. Hip Int. 2010;20:64-74.

42. Ning GZ, Kan SL, Chen LX, Shangguan L, Feng SQ, Zhou Y. Rivaroxaban for thromboprophylaxis after total hip or knee arthroplasty: a meta-analysis with trial sequential analysis of randomized controlled trials. Sci Rep. 2016;6: 23726.

43. Feng W, Wu K, Liu Z, Kong G, Deng Z, Chen S, et al. Oral direct factor Xa inhibitor versus enoxaparin for thromboprophylaxis after hip or knee arthroplasty: systemic review, traditional meta-analysis, dose-response metaanalysis and network meta-analysis. Thromb Res. 2015;136:1133-44.

44. Gómez-Outes A, Terleira-Fernández Al, Suárez-Gea ML, Vargas-Castrillón E. Dabigatran, rivaroxaban, or apixaban versus enoxaparin for thromboprophylaxis after total hip or knee replacement: systematic review, meta-analysis, and indirect treatment comparisons. BMJ. 2012;344

45. Wolowacz SE, Roskell NS, Plumb JM, Caprini JA, Eriksson BI. Efficacy and safety of dabigatran etexilate for the prevention of venous thromboembolism following total hip or knee arthroplasty. A meta-analysis Thromb Haemost. 2009;101:77-85.

46. Cohen AT, Hirst C, Sherrill B, Holmes P, Fidan D. Meta-analysis of trials comparing ximelagatran with low molecular weight heparin for prevention of venous thromboembolism after major orthopaedic surgery. $\mathrm{Br}$ J Surg. 2005:92:1335-44.

47. Ma G, Zhang R, Wu X, Wang D, Ying K. Direct factor Xa inhibitors (rivaroxaban and apixaban) versus enoxaparin for the prevention of venous thromboembolism after total knee replacement: A meta-analysis of 6 randomized clinical trials. Thromb Res. 2015:135:816-22.

48. Neumann I, Rada G, Claro JC, Carrasco-Labra A, Thorlund K, Akl EA, et al. Oral direct Factor Xa inhibitors versus low-molecular-weight heparin to prevent venous thromboembolism in patients undergoing total hip or knee replacement: a systematic review and meta-analysis. Ann Intern Med. 2012;156:710-9.

49. Nieto JA, Espada NG, Merino RG, González TC. Dabigatran, rivaroxaban and apixaban versus enoxaparin for thomboprophylaxis after total knee or hip arthroplasty: pool-analysis of phase III randomized clinical trials. Thromb Res. 2012;130:183-91.

50. Li XM, Sun SG, Zhang WD. Apixaban versus enoxaparin for thromboprophylaxis after total hip or knee arthroplasty: a meta-analysis of randomized controlled trials. Chin Med J. 2012;125:2339-45.

51. Raskob GE, Gallus AS, Pineo GF, Chen D, Ramirez LM, Wright RT, et al. Apixaban versus enoxaparin for thromboprophylaxis after hip or knee replacement: pooled analysis of major venous thromboembolism and bleeding in 8464 patients from the ADVANCE-2 and ADVANCE-3 trials. $J$ Bone Joint Surg Br. 2012;94:257-64.

52. Huang J, Cao Y, Liao C, Wu L, Gao F. Apixaban versus enoxaparin in patients with total knee arthroplasty. A meta-analysis of randomised trials. Thromb Haemost. 2011;105:245-53.

53. Cao YB, Zhang JD, Shen H, Jiang YY. Rivaroxaban versus enoxaparin for thromboprophylaxis after total hip or knee arthroplasty: a meta-analysis of randomized controlled trials. Eur J Clin Pharmacol. 2010;66:1099-108.

54. Melillo SN, Scanlon JV, Exter BP, Steinberg M, Jarvis Cl. Rivaroxaban for thromboprophylaxis in patients undergoing major orthopedic surgery. Ann Pharmacother. 2010;44:1061-71. 
55. Eriksson Bl, Dahl OE, Rosencher N, Clemens A, Hantel S, Feuring M, et al. Oral dabigatran etexilate versus enoxaparin for venous thromboembolism prevention after total hip arthroplasty: pooled analysis of two phase 3 randomized trials. Thromb J. 2015;13:36.

56. Friedman RJ, Dahl OE, Rosencher N, Caprini JA, Kurth AA, Francis CW, et al. Dabigatran versus enoxaparin for prevention of venous thromboembolism after hip or knee arthroplasty: a pooled analysis of three trials. Thromb Res. 2010;126:175-82.

57. Kwok CS, Pradhan S, Yeong JK, Loke YK. Relative effects of two different enoxaparin regimens as comparators against newer oral anticoagulants: meta-analysis and adjusted indirect comparison. Chest. 2013;144:593-600.

Ready to submit your research? Choose BMC and benefit from:

- fast, convenient online submission

- thorough peer review by experienced researchers in your field

- rapid publication on acceptance

- support for research data, including large and complex data types

- gold Open Access which fosters wider collaboration and increased citations

- maximum visibility for your research: over $100 \mathrm{M}$ website views per year

At $\mathrm{BMC}$, research is always in progress.

Learn more biomedcentral.com/submissions 